\title{
Yenilikçi Davranış Ölçeğinin (YDÖ) Türkiye'ye Uyarlama Çalışması
}

\author{
Adaptation Study of the Innovative Behavior Inventory (IBI) to Turkey
}

\section{Dr. Osman PALA ${ }^{1}$ - Arş. Gör. Nuray TURAN²}

Başvuru Tarihi: 12.07.2019

Kabul Tarihi: 01.09.2020

Makale Türü: Araştırma Makalesi

Öz

Bu araştırmanın amacı, Lukes ve Stephan'ın (2017) geliştirdiği Yenilikçi Davranış Ölçeği (YDÖ) Türkçe formunun geçerlilik ve güvenirliğini test etmektir. Çalışmanın örneklemi akademisyenlerden oluşmaktadır. Elde edilen bulgular, ölçeğin orjinali ile aynı faktörlere sahip olduğunu göstermiştir. Bunlar "fikir üretimi, fikir arama, fikir iletişimi, uygulamaya başlama faaliyetleri, diğerlerini dahil etme, engellerin üstesinden gelme ve yenilikçi çıktı" olmak üzere yedi faktördür. Ölçeğin içsel tutarlılık ve güvenilirlik değerleri hem ölçeğin geneli hem de tüm faktörler için uygun çıkmış ve sonuçlar birlikte değerlendirildiğinde ölçeğin tamamının güvenilir olduğu görülmüşı̈̈r. Genel olarak yapılan analizler dikkate alındığında, Türkiye’de yenilikçi davranışı ölçmek amacıyla uyarlanan bu ölçeğin geçerli ve güvenilir bir ölçme aracı olduğunu söylemek mümkündür. Böylece ölçeğin, gelişime açık bir alan olarak yenilikçi davranışölçümü için yararlı olacağı düşünülmekte, gelecekte farklı araştırmalarda bağıml ve bağımsız değişken olarak kullanılması önerilmektedir. Aynı zamanda ölçeğin bu haliyle organizasyonlar için uygulamada çalışan davranışı ölçümlerine ve geliştirilecek eğitim-geliştirme programları ile projelere destek olacağı öngörülmektedir.

Anahtar Kelimeler: Yenilikçi Davranış, Yenilikçi İş Davranışı, Yenilikçi Davranış Ölçeği, Ölçek Uyarlama

\begin{abstract}
The aim of this study is to test the validity and reliability of the Turkish version of the Innovative Behaviour Inventory (IBI) developed by Lukes and Stephan (2017). The sample of the study consists of academicians. The findings indicated that the scale had the same factors as the original. These are seven factors: "idea generation, idea search, idea communication, implementation starting activities, involving others, overcoming obstacles and innovation outputs". The internal consistency and reliability values of the scale were found appropriate both for the overall scale and for all factors. When these results are evaluated together, it is seen that the whole scale is reliable.
\end{abstract}

\footnotetext{
${ }^{1}$ Karamanoğlu Mehmet Bey Üniversitesi İİBF Ekonometri Bölümü, osmanpala@kmu.edu.tr, ORCID: 0000-0002-2634-2653

${ }^{2}$ Karamanoğlu Mehmet Bey Üniversitesi İİBF ÇEKO Bölümü, nurayturan@yahoo.com, ORCID: 0000-0001-6823-3992
} 
In general, considering the analyzes made, it is possible to say the scale which is adapted to measure innovative work behavior in Turkey is a valid and reliable instrument. Thus, the scale is thought to be useful for measuring innovative work behavior as an area open to development; it is recommended to be used as dependent and independent variable in different studies in the future. At the same time, the scale is anticipated that the scale will support projects that work in practice for organizations and training and development programs to be developed.

Keywords: Innovative Behavior, Innovative Work Behavior, Innovative Behavior Inventory, Scale Adaptation

\section{Giriş}

Yenilikçi Davranış (YD), çalışma yaşamı bağlamında güncel literatürde öne çıkan önemli bir konudur. Teknolojik gelişme ve küreselleşme sektörlerin, çalışma biçimlerinin, çalışma yaşamının gerektirdiği yetkinliklerde öne çıan beklentilerdeki ve organizasyonların rekabet koşullarındaki değişim sonucunda YD odak noktası haline gelmiştir.

Organizasyon ve çalışanlar açısından yenilik- yenilikçilik- yaratıcılık olgularının hem arka planının, hem de süreç ve sonucu olarak YD’nin farkına varılması ile birlikte psikoloji ve davranış bilimlerinin birleşiminden oluşan bir araştırma konusu ortaya çıkmıştır. Böylece, uluslararası bağlamda YD'in ölçümü ve çıtılları üzerine odaklanan araştırmalar çeşitli sektörlerde birbirinden farklı örneklemlerle devam etmektedir. Böylece, ülkemizde de güncel ve kapsamlı bir ölçüm aracının benimsenmesinin araştırmalar açısından oldukça önemli olduğu görülmektedir. Bu bağlamda YD kavramını değerlendirmek ve ölçmek için 2017 yllında Lukes ve Stephan tarafından geliştirilmiş Yenilikçi Davranış Ölçeği'nin (YDÖ) Türkçe geçerlilik-güvenilirlik çalışmasının yapılarak literatüre kazandırılması uygun görülmüştür. İlgili ölçek teorik temellerini geçmişten bugüne yenilikçi davranış ölçümlerine yönelik geliştirilmiş ölçekler ve boyutları ile yenilikçi davranışın farklı alanlardaki tanım ve içeriklerinden almıştır. Araştırmacılar, uyarlaması yapılan ölçekte çalışanların yenilikçi davranışını çok yönlü bir olgu olarak ölçmek ve anlamak amaciyla geliştirmişlerdir. Bahsi geçen ölçek, organizasyonlardaki yenilikçi davranışı açıklayan ve destekleyen önemli mikro temellerin daha iyi anlaşılmasını sağlama amacına sahiptir (Lukes ve Stephan, 2017, s.137).

YDÖ için literatürde farklı toplum ve ülkelere uyarlama ve uygulama çalışmaları mevcuttur. Örneğin Duradoni ve Di Fabio'nun (2019) İtalya'da 120 öğretmen ile yaptıkları YDÖ uyarlama çalışmasında ölçeği 23 madde ve 7 faktörlü olarak ele almışlar, ölçeğin uyarlama modelinin iyi uyum sağladığını ifade etmişlerdir. Benzer biçimde Mahgoub ve arkadaşları (2019) Mısır'da bir üniversite hastanesinde çalışan 203 hemşire ile yine aynı ölçeği kullanarak çalışanlar arasında YD değerlendirmesi yapmışlardır. Elde ettikleri sonuçlara göre; çalışma ortamı ve YD arasında güçlü bir korelasyon tespit etmişler. Sönmez ve arkadaşları (2019) ise; Türkiye'de iki farklı hastanede çalışan 360 hemşire ile yaptıkları çalışma sonucunda YD ölçeğini 6 faktörlü olarak uygulamışlar ve yedinci faktörün ayrı olarak ele alındığını ifade etmişlerdir. Ölçeğe ilişkin analiz 
sonuçlarında, uyarlanan ölçek modelinin iyi uyum sağladığını belirtmişlerdir. Ancak her ne kadar Sönmez ve arkadaşları (2019) çalışmalarında YD ölçeğini Türkiye'de uyarlamış olsalar da makale dili olarak İngilizce kullandıkları, ölçeğin Türkçe formunu vermedikleri dikkat çekmiştir. Bunun yanı sıra farklı bir kültüre uyarladıkları ölçeğin o kültüre özgü davranışı gözlemleyebilecekleri Açımlayıcı Faktör Analizi (AFA) yapmadıkları görülmüştür. Böylece, bu çalışmada YDÖ’nün Türk çalışma yaşamındaki davranışın gözlemlenmesi ve doğrulanabilmesi için AFA'dan faydalanılarak Türkçe’ye kazandırılmasının önemli olduğu düşünülmüştür.

\section{Literatür Tarama}

YD çalışanların yeni, faydalı ve özgün fikir, süreç, hizmetler ile ürünleri çalışma ortamına katmayı amaçlayan davranışlarını (Farr ve Ford, 1990); fikirlere öncülük edilmesini (De Jong ve Den Hartog, 2010, s.19); yeniliğin temel yapı taşları olarak fikir üretimi ve ortaya çıkan bu fikri uygulamayı kapsayan (Krause, 2004, s.98), bu fikirlerin çalışanın iş rolüne ve organizasyona tanitılması, uygulanması (Vasanthapriyan, 2019) olarak tanımlanmaktadır. Bunların yanı sıra YD doğrudan veya dolaylı olarak organizasyon verimliliğini etkileyen organizasyon üyelerinin faaliyet ve etkileşimi olarak (http://www.businessdictionary.com/article/657/creativity-and-innovation-in-the-workplace/, 04.07.2019) ve çoğu çalışanın işinin tipik bir parçası olmayan, görev tanımında belirtilmeyen isteğe bağlı ekstra rol davranışı (Katz ve Kahn, 1978) olarak görülmektedir. Organizasyonlar ise; bahsi geçen ekstra rol davranışına her zaman yeni ve olağandışı koşullara uyum sağlayabilmek için ihtiyaç duymaktadır (West ve Farr, 1990; Woodman vd., 1993; Shalley, 1995; Oldham ve Cummings, 1996; Jafri, 2010).

Gerek yenilikçi iş davranışı gerek yenilikçi davranış olarak ifade edilen ve aynı içeriğe sahip olan extra rol davranışı organizasyonlarda ürünlerde, hizmetlerde ve süreçlerde yeni fikirlerin kabulü ve başarılı bir biçimde uygulanmasını ifade etmektedir (Thompson, 1965). Başka bir ifadeyle bir organizasyona fayda sağlayan ve önemli bir değere sahip yeni ürün ve hizmet ortaya konması YD olarak tanımlanmaktadır (Woodman vd., 1993). Benzer biçimde yeni bir fikir ya da fikirlerin organizasyona aktarımı ve pratikte uygulanması (Van de Ven, 1989) ya da organizasyonda yeni ürün geliştirme ya da üretim ve yönetim sistemlerinde yeni geliştirmeler yapmak (Gareth, 2001); hizmet ve ürün üretiminde yeni üretim metotlarının uygulanması, çalışma süreçlerinde yeni yöntemlerin geliştirilmesi YD’yi tanımlar (Samuel, 2000, s. 519). Aynı şekilde organizasyon çevresinde ortaya çıkan değişimlere uyum gösterebilmesi için organizasyon kültüründe bir değer meydana getirilmesi de YD'dir (Buckler, 1996). Böylece, YD’nin çok boyutlu bir yapıya sahip olduğunu söylemek mümkündür.

Sonuç olarak çok boyutlu bir süreç olarak özgün ve yeni fikirlerin tanıtımı ve uygulamasını ifade eden YD (Xerri ve Brunetto, 2013, s. 3167) giderek çok yönlü gelişim gösteren bir yapıya sahip olmuş (Krause, 2004, s. 98), YD ile ilgili çalışmaların çoğu genellikle yeniliğin her aşamasında çok faktörlü bir süreç olarak yer almıştır (De Jong ve Den Hartog, 2010, s. 24). YD bazı çalışmalarda "fikrin üretilmesi ve test edilmesi ile uygulama (Krause, 2004, s. 89)", "fikrin üretilmesi ve uygulanması (Niesen vd., 2018, s. 176)” olmak üzere iki faktörlü kabul görürken; bazı araştırmalarda "fikri savunma, fikir için destek görme; fikri uygulama, kuruluş ve 
gerçekleştirme" (Veenendaal ve Bondarouk, 2015, s. 142) olarak üç temel faktör olarak ele alınmıştır. De Jong ve Den Hartog (2010) “fikir/fırsatları keşfetme, fikir üretme, fikri savunma ve uygulama” (De Jong ve Den Hartog, 2010, s. 24) olmak üzere dört faktör; Kleysen ve Street (2001) ise; "fırsat arama, üretme, biçimlendirici soruşturma, destekleme ve uygulama" (Kleysen ve Street, 2001, s. 285) olarak beş faktör ortaya atmıştır. Son olarak 2017 yılında Lukes ve Stephan "fikir üretimi, fikir arama, fikir iletişimi, uygulamaya başlama faaliyetleri, diğerlerini dâhil etme, engellerin üstesinden gelme ve yenilikçi çıtılar olarak" yedi faktör önermiştir (Lukes ve Stephan, 2017, s. 38). YD’ye ilişkin literatürde farklı araştırmacılar tarafından ortaya atılan çeşitli faktörlerin yer aldığı bir içerik Tablo 1'de yer almaktadır.

\section{Tablo 1. Literatürde Yer Alan YD Faktörleri}

\begin{tabular}{|c|c|}
\hline Yazar/Yazarlar & Süreç \\
\hline Kanter (1988) & $\begin{array}{ll}\text { 1. fikir üretimi } \\
\text { 2. fikir için destek arayışı } \\
\text { 3. fikirlerin gerçekleştirilmesi } \\
\text { 4. yeniliklerin yayılması }\end{array}$ \\
\hline Scott \& Bruce (1994: 582) & $\begin{array}{l}\text { 1. fikrin üretilmesi } \\
\text { 2. koalisyon kurma } \\
\text { 3. fikrin uygulanması }\end{array}$ \\
\hline Kleysen \& Street (2001: 285) & $\begin{array}{ll}\text { 1. } & \text { firsat arama } \\
\text { 2. } & \text { üretme } \\
\text { 3. } & \text { biçimlendirici soruşturma } \\
\text { 4. } & \text { destekleme } \\
5 . & \text { uygulama }\end{array}$ \\
\hline Krause (2004) & $\begin{array}{l}\text { 1. fikirlerin üretilmesi ve test edilmesi } \\
\text { 2. uygulama }\end{array}$ \\
\hline Dorenbosch vd. (2005, s. 131) & $\begin{array}{l}\text { 1. yaratıcılık-odaklı iş davranışı } \\
\text { 2. uygulama odaklı iş davranışı } \\
\text { 3. bilgisayar teknolojisinin kullanımına yönelik yenilikçi davranış } \\
\text { 4. finansal kaynakların kullanımına yönelik yenilikçi davranışlar }\end{array}$ \\
\hline De Jong \& Den Hartog (2010, s. 24) & $\begin{array}{l}\text { 1. fikir veya firsatları keşfetme } \\
\text { 2. fikir üretme } \\
\text { 3. fikri savunma } \\
\text { 4. uygulama }\end{array}$ \\
\hline Kheng vd. (2013) & $\begin{array}{l}\text { 1. başlangıç aşaması } \\
\text { 1.1. firsat araştırması } \\
\text { 1.2. fikir üretimi } \\
\text { uygulama aşaması } \\
\text { 2.1. fikrin tanıtılması ve desteklenmesi } \\
\text { 2.2. fikrin uygulanması }\end{array}$ \\
\hline Veenendaal \& Bondarouk (2015, s. 142) & $\begin{array}{l}\text { 1. fikir üretimi, problemin farkına varma ve yeni firsatları keşfetme } \\
\text { 2. fikri savunma, fikir için destek görme } \\
\text { 3. fikri uygulama, kuruluş ve gerçekleştirme }\end{array}$ \\
\hline Lukes \& Stephan $(2017$, s. 38$)$ & $\begin{array}{ll}\text { 1. } & \text { fikir üretimi } \\
2 . & \text { fikir arama } \\
\text { 3. fikir iletişimi } \\
\text { 4. } \\
\text { 5. dygulamaya başlama faaliyetleri } \\
\text { 6. engellerin dahil etstesinden gelme } \\
\text { 7. yenilikçi çıtıllar }\end{array}$ \\
\hline Niesen vd. (2018, s. 176) & $\begin{array}{l}\text { 1. fikirlerin üretilmesi } \\
\text { 2. fikirlerin uygulanması }\end{array}$ \\
\hline
\end{tabular}




\section{Metodoloji}

YDÖ’nün Türkçe uyarlamasını yapabilmek için, öncelikle İngilizce-Türkçe ve Türkçe-İngilizce çevirileri yapılmış ardından ilgili istatistiki analizler yapılmıştır. Bu makalede Türkçe uyarlaması yapılan ölçek, Lukes ve Stephan tarafından 2017 yılında geliştirilen Innovative Behavior Inventory (IBI) - Yenilikçi Davranış Ölçeği'dir (YDÖ).

Araştırmanın örneklemini, Türkiye'de eğitim - öğretim faaliyetinde bulunan çeşitli devlet üniversitelerinde görev yapmakta olan 122 akademisyen oluşturmaktadır. Örneklem olarak akademisyenlerin seçilme sebebi, tüm dünyada olduğu gibi ülkemiz geleceğinde de önemli etkilere sahip üniversitelerde görev yapan akademisyenlerin yenilikçi davranışta kilit rollerinin olduğunun düşünülmesidir. Ayrıca YDÖ’nün çalışma yaşamında yenilikçi yaklaşımları ölçmeye, değerlendirmeye ve bu yaklaşımların faktörlerini incelemeye yönelik olması, akademisyenlerin de çalışma yaşamlarında sürekli olarak güncel gelişmeleri takip ederek proje, araştırma ve çalışmalarında yeni bakış açılarına ve fikirlere odaklanmak durumunda olması örneklem olmalarında bir başka unsur olmuştur. Çalışma ortamları ve yaptıkları işleri gereği yenilikçi davranışın tüm süreçleriyle sıklıkla karşı karşıya gelen akademisyenlerden anket yoluyla ulaşılan, farklı fakülte ve bölümlere mensup kişilerle çalışma gerçekleştirilmiştir. Çalışmada YDÖ örneklemi akademisyenlerden oluştuğu için çalışmanın kapsamı akademi ile sınırlandırılmıştır. Bu nedenle çıkarsamalar bu meslek grubuna yönelik gerçekleştirilmiştir.

YDÖ'nün orijinalinde yer alan maddeler önce araştırmacılar, ardından alanında uzman iki akademisyen tarafından Türkçe'ye çevrilmiştir. Sonraki adımda yapılan çeviriler anlam ve kapsam bakımından incelenmiş, karşılaştırmalar yapılmış ve Türkçe form oluşturulmuş, bu form için iki Türkçe öğretmeninin görüşü alınmıştır. Ardından Türkçe formun İngilizce geri çevirisi yapılmış ve orijinal ölçek ile karşılaştırılarak form üzerinde gerekli düzeltme ve düzenlemeler yapılmış, ölçeğin Türkçe formu oluşturulmuştur. En son aşamada ise; çeviri ölçek, ölçeğin özgün formu ile karşılaştırılmış ve uygulamaya hazır hale getirilmiştir.

Anket aracılığgyla toplanan veriler öncelikle gerekli olan veri ön işleme süreçlerinden geçirilmiş ve sonrasinda istatistiki analizler SPSS-21 ve AMOS 26 yazılım ortamlarında gerçekleştirilmiştir. YDÖ orijinal ölçeğin geliştirildiği ülkeden farklı bir çalışma yaşamına sahip Türkiye'de doğru bir uyarlama yapılabilmesi için; veri setine ilk önce Açımlayıcı Faktör Analizi (AFA) uygulanmış ve ölçeğe dair faktör yapısı ortaya çıkarılmıştır. AFA sonucu ortaya çıkan faktör bileşenlerinin yapı geçerliliği Doğrulayıcı Faktör Analizi (DFA) ile değerlendirilmiştir. Faktör analizi öncesi örneklem büyüklüğü Kaiser-Meyer-Olkin (KMO) değerine bakılmış ve hesaplanan 0,912 değerinin kabul sınırı olarak 0,70’in üzerinde olduğu görülerek faktör analizi için veri büyüklüğünün uygun olduğu tespit edilmiştir (Hair vd., 2010, s.104). Verilere faktör analizi uygulanabilmesi için gereken bir başka değerlendirme ise Bartlett küresellik testi olup, yapılan test sonucunda ortaya çıkan $(\chi 2=1575,853$; s.d. $=253$; $\mathrm{p}<0.000)$ değerler ile verilere faktör analizi uygulanmasında bir sakınca olmadığı tespit edilmiştir. 


\section{Açımlayıcı Faktör Analizi}

23 madde ile ifade edilen YDÖ öncelikle AFA ile temel bileşenler metodu kullanılarak faktör analizine tabi tutulmuştur. Türkçe'ye uyarlanan YDÖ faktör sayısını tespit etmek için bileşen özdeğerlerinin bulunduğu, Şekil 1'de görüldüğü gibi elde edilen faktör özdeğer grafiği (Tabachnick ve Fidell, 2001) ve ayrıca özdeğer limit değerleri açısından Jolliffe kriteri (Jolliffe, 2002, s. 115) dikkate alınmıştır. AFA sonucu, orijinal ölçekte olduğu gibi, Jolliffe kriterine uyan yedi faktörlü bir yapı ortaya çıkmıştır.

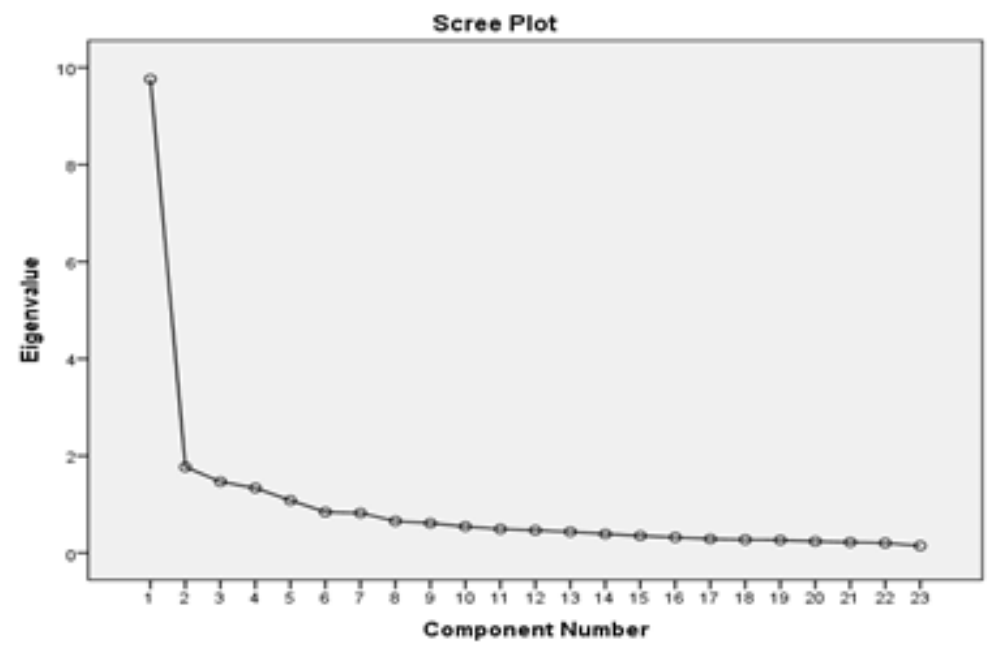

Şekil 1. Faktör Özdĕger Grafĭ̆i

Yedi faktörün ölçeğe dair açılladı̆̆ 1 toplam varyans \% 74,293 olmuştur. Elde edilen yedi faktörlü yapının yorumlamada açıklık kazanması için "Varimax" metodu ile eksen döndürmesinin yapılması sonucunda ortaya çıkan faktör yapısı ile faktör yükü dağılımı Tablo 2 'de yer almaktadır. 


\section{Tablo 2. Varimax Rotasyonu Sonucu Ortaya Çıkan Faktör Yükü Dă̆ılımı}

Döndürülmüs Bileșen Matrisi

\begin{tabular}{|c|c|c|c|c|c|c|c|c|}
\hline Madde No & Madde Adı & $\begin{array}{l}\text { (F1) } \\
\text { Fikir Üretimi }\end{array}$ & $\begin{array}{l}\text { (F2) } \\
\text { Fikir } \\
\text { Arama }\end{array}$ & $\begin{array}{l}\text { F(3) } \\
\text { Fikir } \\
\text { Iletişimi }\end{array}$ & $\begin{array}{c}\text { F(4) } \\
\text { Uygulamay } \\
\text { a Başlama } \\
\text { Faaliyetleri }\end{array}$ & $\begin{array}{l}\quad \mathbf{F ( 5 )} \\
\text { Diğerlerini } \\
\text { Dâhil } \\
\text { Etme }\end{array}$ & $\begin{array}{c}\mathbf{F}(\mathbf{6}) \\
\text { Engellerin } \\
\text { Üstesinden } \\
\text { Gelme }\end{array}$ & $\begin{array}{l}\mathbf{F}(7) \\
\text { Yenilikçi } \\
\text { Çıktılar }\end{array}$ \\
\hline V1 & $\begin{array}{l}\text { İşimi yaparken yeni } \\
\text { yollar denerim. }\end{array}$ & ,804 & 242 & ,118 & , 163 & ,111 & ,173 & , 128 \\
\hline $\mathrm{V} 2$ & $\begin{array}{l}\text { Özgün düşünmeyi } \\
\text { gerektiren işleri tercih } \\
\text { ederim. }\end{array}$ & 690 & ,148 & ,282 & , 199 & ,124 & ,285 & ,110 \\
\hline V3 & $\begin{array}{l}\text { İşimde bir şeyler iyi } \\
\text { gitmediğinde, yeni } \\
\text { çözüm yolları } \\
\text { bulmayı denerim. }\end{array}$ & ,662 & ,196 &, 014 &, 226 & , 197 &, 325 & ,009 \\
\hline V4 & $\begin{array}{c}\text { Meslektaş veya } \\
\text { iş ortaklarımdan } \\
\text { yeni fikirler almaya } \\
\text { çalışırım. }\end{array}$ & ,218 & ,652 & ,295 &,- 047 & ,278 & ,199 & ,113 \\
\hline V5 & $\begin{array}{c}\text { Kendi işimde } \\
\text { yararlanmak için, } \\
\text { başka yerlerde işlerin } \\
\text { nasıl yapıldı̆̆ ile } \\
\text { ilgilenirim. }\end{array}$ & ,166 & ,760 &, 043 &, 287 & ,132 &, 031 & ,162 \\
\hline V6 & $\begin{array}{l}\text { En iyisini bulmak ve } \\
\text { uygulamak için diğer } \\
\text { insanların yeni } \\
\text { fikirlerini araştırırım. }\end{array}$ & ,293 & ,624 &, 179 &, 246 &, 228 & ,306 &,- 062 \\
\hline V7 & $\begin{array}{c}\text { Yeni bir fikrim } \\
\text { olduğunda, iş } \\
\text { arkadaşlarıma bu fikri } \\
\text { benimsetmeye } \\
\text { çalışırım. }\end{array}$ &, 035 & ,256 & ,774 &, 084 &, 056 &, 152 &, 173 \\
\hline V8 & $\begin{array}{l}\text { Yeni bir fikrim } \\
\text { olduğunda, } \\
\text { yönetimden buna } \\
\text { destek almaya } \\
\text { çalışırım. }\end{array}$ & ,202 &,- 096 & ,648 &, 146 & ,418 & ,122 & , 154 \\
\hline V9 & $\begin{array}{l}\text { İş arkadaşlarıma yeni } \\
\text { fikirlerin olumlu } \\
\text { yönlerini göstermeye } \\
\text { çalışırım. }\end{array}$ & ,092 & ,138 & ,861 &, 047 & ,159 & ,106 &,- 041 \\
\hline V10 & $\begin{array}{c}\text { Yeni bir fikrim } \\
\text { olduğunda, bu fikir } \\
\text { üzerinde çalışabilecek } \\
\text { insanları işbirliğine } \\
\text { dâhil etmeye } \\
\text { çalışırım. }\end{array}$ &, 218 & ,095 & ,619 &, 371 & ,303 & ,226 &, 087 \\
\hline V11 & $\begin{array}{l}\text { Yeni fikirlerin } \\
\text { uygulanması için } \\
\text { uygun planlar ve } \\
\text { zaman programları } \\
\text { geliştiririm. }\end{array}$ & ,079 & ,098 &, 381 &, 594 & ,097 & ,392 &, 072 \\
\hline V12 & $\begin{array}{l}\text { Yeni fikirlerin } \\
\text { uygulanması için yeni } \\
\text { teknoloji, süreç ya da } \\
\text { prosedür araştırırım. }\end{array}$ & , 199 & ,281 & ,074 & ,742 & , 162 &, 320 & ,009 \\
\hline
\end{tabular}


Tablo 2. Varimax Rotasyonu Sonucu Ortaya Çıkan Faktör Yükü Dağılımı (Devamı)

\begin{tabular}{|c|c|c|c|c|c|c|c|c|}
\hline V13 & $\begin{array}{l}\text { Yeni fikirlerin } \\
\text { uygulanması için } \\
\text { ihtiyaç duyulan } \\
\text { araçları/malzemeleri } \\
\text { araştırır, temin } \\
\text { ederim. }\end{array}$ & ,306 &, 120 & , 109 & ,750 & , 184 & ,130 & ,099 \\
\hline V14 & $\begin{array}{l}\text { Uygulama sırasında } \\
\text { sorunlar ortaya } \\
\text { çıarsa, onları } \\
\text { çözebilecek } \\
\text { kişilere/ehil ellere } \\
\text { teslim ederim. }\end{array}$ &, 140 & ,477 & ,116 & , 146 & ,666 & , 102 & ,076 \\
\hline V15 & $\begin{array}{c}\text { Bir fikrin } \\
\text { uygulanmasına kilit } \\
\text { karar vericileri de } \\
\text { dâhil etmeye } \\
\text { çalışırım. }\end{array}$ & ,279 & ,159 &, 256 & ,209 & ,706 &, 182 &, 072 \\
\hline V16 & $\begin{array}{c}\text { Yeni bir fikrim } \\
\text { olduğunda, onu } \\
\text { sahiplenecek/sırtlanac } \\
\text { ak insanlar bulmaya } \\
\text { çalışırım. }\end{array}$ & ,016 & ,155 & ,226 & , 101 & ,753 &, 214 &, 020 \\
\hline V17 & $\begin{array}{l}\text { Bir fikri geliştirirken } \\
\text { karşıma çıkan } \\
\text { engellerin kararlılıkla } \\
\text { üstesinden } \\
\text { gelebilirim. }\end{array}$ & , 197 &, 117 & , 165 & ,303 & ,056 &, 763 &, 053 \\
\hline V18 & $\begin{array}{c}\text { Başkaları } \\
\text { yapılamayacağını } \\
\text { söylese bile pes } \\
\text { etmem. }\end{array}$ & ,198 & ,099 & , 190 & ,171 & ,068 & ,804 &, 051 \\
\hline V19 & $\begin{array}{l}\text { Genellikle amacima } \\
\text { ulaşana kadar } \\
\text { durmam. }\end{array}$ & , 199 & ,114 &, 228 & ,208 &, 214 & ,773 & ,201 \\
\hline V20 & $\begin{array}{l}\text { Bir fikri uygularken } \\
\text { işler planladığım gibi } \\
\text { gitmese bile } \\
\text { çalışmaya devam } \\
\text { ederim. }\end{array}$ &, 169 & ,127 &, 018 & ,039 &, 247 & ,785 &, 110 \\
\hline V21 & $\begin{array}{c}\text { Fikirlerimi } \\
\text { benimsetme ve hayata } \\
\text { geçirmede siklıkla } \\
\text { başarılı oldum. }\end{array}$ & ,183 & ,404 & ,382 & ,085 & ,095 & ,355 & ,410 \\
\hline V22 & $\begin{array}{c}\text { Düşündüğüm birçok } \\
\text { şey kuruluşumuzda } \\
\text { uygulanmakta, } \\
\text { kullanılmaktadır. }\end{array}$ & ,013 & ,057 & ,057 & ,007 &, 116 & ,091 & ,912 \\
\hline V23 & $\begin{array}{l}\text { Ne zaman bir yerde } \\
\text { çalıştıysam, orada bir } \\
\text { şeyleri iyileştirdim. }\end{array}$ & ,416 & ,202 & ,222 & ,220 &,- 070 &, 235 & ,610 \\
\hline \multicolumn{2}{|c|}{ Özdeğerler } & 2,410 & 2,254 & 2,964 & 2,193 & 2,229 & 3,446 & 1,590 \\
\hline \multicolumn{2}{|c|}{ Varyans Açıklama Yüzdeleri } & $10,48 \%$ & $9,8 \%$ & $12,89 \%$ & $9,54 \%$ & $9,69 \%$ & $14,98 \%$ & $6,91 \%$ \\
\hline \multicolumn{2}{|c|}{ Cronbach Alfa Katsayıları } & 0,814 & 0,767 & 0,843 & 0,792 & 0,793 & 0,891 & 0,715 \\
\hline
\end{tabular}

Tablo 2'de yer alan sonuçlar değerlendirildiğinde maddeler en yüksek yüklere göre faktörlere ayrılmış ve yük değerlerinin ilgili faktörlerin çoğu için en az 0,60 sahip olması nedeniyle madde dağılımlarının faktörler için uygun olduğu görülmüştür. 
Türkçe'ye uyarlanan YDÖ'de, orijinal ölçekteki gibi yedi faktör bulunmuş ve her bir faktördeki maddeler orijinal ölçekteki maddeler ile birebir aynı faktörler içinde yer almıştır. Sonuçlara bakıldığında Türkiye örnekleminde yer alan akademisyen grubunun YDÖ bakımından Lukes ve Stephan (2017) tarafından yapılan çalışmadaki örneklem ile benzer bakış açılarına sahip olduğu düşünülmektedir. Bunun yanısıra, ölçeğin içsel tutarlılığını ve güvenilirliğini belirleyen bir ölçüt olan Cronbach Alfa katsayısı ölçeğin geneli için 0,935 bulunmuş ve faktörler için ayrı ayrı hesaplanan Cronbach Alfa katsayıları da Tablo 2'de görüldüğü gibi yüksek ve yeterli çıkmıştır. Bu sonuçlar birlikte değerlendirildiğinde ölçeğin tamamının güvenilir olduğu görülmektedir.

\section{Doğrulayıcı Faktör Analizi}

AFA sonrasında ortaya çıan yedi faktöre sahip ölçeğin geçerliliği DFA ile değerlendirilmiştir. AMOS 26 paket yazılımı ile modelin analizi sonucu DFA yapısı ise; Şekil 2'deki gibidir.

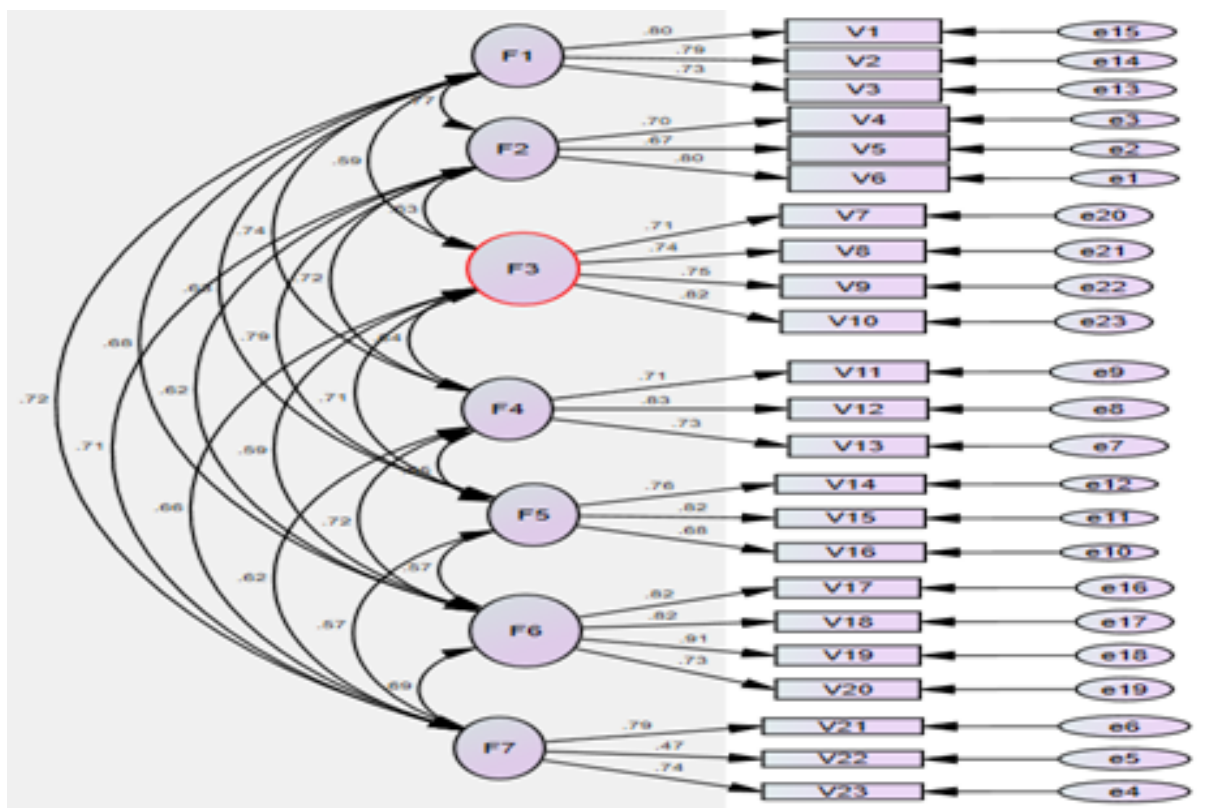

Şekil 2. YDÖ’nün 7 Faktörlï Model için DFA Sonuçları

Ölçeğin yedi faktörlü yapısının yakınsaklık geçerliği DFA ile değerlendirildiğinde öncelikle Şekil 2'de görüldüğü gibi her bir faktör yükünün oldukça yüksek ve anlamlı çıktığ1 görülmektedir. 23 maddenin 20 adeti istenen değer olan 0,70'den büyük ve diğer üç madde de 0,40'dan büyük faktör yüküne sahip olduğu için modelin kabul edilirliği bulunmaktadır. Ortalama varyans açılama değeri olarak ifade edilen ve modelin yakınsaklık geçerliliğini belirleyen AVE için kabul edilebilir değer olarak 0,50 ve üzeri, yapısal geçerlilik ve güvenilirlik değeri olan ve bileşik güvenilirlik olarak ifade edilen CR için kabul edilebilir değer ise; 0,60 ve üzeri olarak ifade edilmektedir (Happell vd., 2015, s. 41). Çalışmada modelin AVE değeri 0,58 olarak hesaplanmıştır. Bu nedenle modelin yakınsaklık geçerliliğine sahip olduğu söylenebilir. Modelin CR değerleri ise; her bir faktör için ayrı ayrı hesaplanmakta ve çalışmada bulunan yedi faktörün her biri için 0.70 değerinden büyük elde edilmiştir. Bu sonuçlara göre modelin bir güvenilirliğe sahip olduğu ifade edilebilir. 
Modelin önemli olan uyum istatistikleri incelendiğinde ise; örneklem ile popülasyon arasındaki ilişkiyi kovaryans matrisleri üzerinden ele alan ve Ki Karenin serbestlik derecesine bölümüyle hesaplanan $\chi^{2}$ /s.d. değeri 1,304 olarak elde edilmiştir. $\chi^{2}$ /s.d. üçün altında bulunduğu durumlarda modelin iyi uyum gösterdiği ifade edilmektedir (Kline, 2015, s. 204). Tahmin hataları ortalamalarının karekökünün alınması ile hesaplanan RMSEA için 0,10 ve altı değerin kabul edilir değer olduğu ifade edilmektedir (Kline, 2015: 206). Çalışmada elde edilen RMSEA değeri ise; 0,050 olmuştur. Bu değer, modelin iyi bir uyumu olduğunu göstermektedir. GFI uyum iyiliği indeksi değerinin 0,90 ve üzeri olmasının modelin kabul görmesinde önemli olduğu ifade edilmekle birlikte; bu değerin örneklem büyüklüğünden etkilendiği de söylenmektedir (Evci ve Aylar, 2017, s. 400). Çalışmada GFI değeri 0,845 ile kritik değere yakın bulunmakla birlikte çalışmadaki örneklem sayısının görece küçük olmasının bu değeri etkilemiş olduğu varsayılmaktadır.

Karşılaştırmalı uyum indeksi CFI değerinin ise; modelin uyumluluğu açısından 0,90 ve üstü olması gerekmektedir (Evci ve Aylar, 2017, s. 401). Çalışmada hesaplanan CFI değeri 0,956 olarak ortaya çıkmış ve modelin kabul edilebilirliğini desteklemiştir. Artan uyum indeksi IFI değerinin ise; 0,90 ve üstü olduğunda modelin kabul edilebilir uyuma sahip olduğu ifade edilmektedir (Evci ve Aylar, 2017, s. 401). IFI, model için 0,957 olarak hesaplanmıştır. Genel olarak iyi uyum istatistik sonuçlarının, DFA ile faktör yapısı analiz edilen YDÖ için yedi faktörlü modelin, yapısal geçerliliğinin olduğu gözlenmiştir. Akademisyenler arasında uygulanan YDÖ için maddelere göre ortaya çıkan tanımlayıcı istatistikler Tablo 3'te yer almaktadır.

\section{Tablo 3. YDÖ Maddelerinin Tanımlayıcı İstatistikleri}

\begin{tabular}{|c|c|c|}
\hline F1 Fikir Üretimi & Ortalama & Std. sapma \\
\hline V1 İşimi yaparken yeni yollar denerim. & 3,99 &, 838 \\
\hline V2 Özgün düşünmeyi gerektiren işleri tercih ederim. & 4,18 &, 843 \\
\hline V3 İşimde bir şeyler iyi gitmediğinde, yeni çözüm yolları bulmayı denerim. & 4,31 & ,739 \\
\hline F2 Fikir Arama & Ortalama & Std. sapma \\
\hline V4 Meslektaşlarım veya iş ortaklarımdan yeni fikirler almaya çalışırım. & 4,26 &, 870 \\
\hline V5 Kendi işimde yararlanmak için, başka yerlerde işlerin nasıl yapıldı̆̆ 1 ile ilgilenirim. & 4,09 &, 853 \\
\hline V6 En iyisini bulmak ve uygulamak için diğer insanların yeni fikirlerini araştırırım. & 4,24 & ,783 \\
\hline F3 Fikir İletişimi & Ortalama & Std. sapma \\
\hline V7 Yeni bir fikrim olduğunda, iş arkadaşlarıma bu fikri benimsetmeye çalışırım. & 3,23 & ,960 \\
\hline V8 Yeni bir fikrim olduğunda, yönetimden buna destek almaya çalışırım. & 3,36 & ,971 \\
\hline V9 İş arkadaşlarıma yeni fikirlerin olumlu yönlerini göstermeye çalışırım. & 3,78 & ,886 \\
\hline $\begin{array}{l}\text { V10 Yeni bir fikrim olduğunda, bu fikir üzerinde çalışabilecek insanları işbirliğine dâhil etmeye } \\
\text { çalışırım. }\end{array}$ & 3,80 & ,887 \\
\hline
\end{tabular}


Tablo 3. YDÖ Maddelerinin Tanımlayıcı İstatistikleri (Devamı)

\begin{tabular}{|c|c|c|}
\hline F4 Uygulamaya Başlama Faaliyetleri & Ortalama & Std. sapma \\
\hline V11 Yeni fikirlerin uygulanması için uygun planlar ve zaman programları geliştiririm. & 3,81 & ,875 \\
\hline V12 Yeni fikirlerin uygulanması için yeni teknoloji, süreç veya prosedürler araştırırım. & 3,97 & ,823 \\
\hline V13 Yeni fikirlerin uygulanması için ihtiyaç duyulan araçları/malzemeleri araştırır, temin ederim. & 3,98 & ,808 \\
\hline F5 Diğerlerini Dâhil Etme & Ortalama & Std. sapma \\
\hline $\begin{array}{l}\text { V14 Uygulama sırasında sorunlar ortaya çıkarsa, onları çözebilecek kişilere/ehil ellere teslim } \\
\text { ederim. }\end{array}$ & 3,98 & ,828 \\
\hline V15 Bir fikrin uygulanmasına kilit karar vericileri de dâhil etmeye çalışırım. & 3,91 & ,872 \\
\hline V16 Yeni bir fikrim olduğunda, onu sahiplenecek/sırtlanacak insanlar bulmaya çalışırım. & 3,66 & 993 \\
\hline F6 Engellerin Üstesinden Gelme & Ortalama & Std. sapma \\
\hline V17 Bir fikri geliştirirken karşıma çıkan engellerin kararlılıkla üstesinden gelebilirim. & 3,91 & 843 \\
\hline V18 Başkaları yapılamayacağını söylese bile pes etmem. & 4,09 & ,900 \\
\hline V19 Genellikle amacıma ulaşana kadar durmam. & 4,02 & 909 \\
\hline V20 Bir fikri uygularken işler planladığım gibi gitmese bile çalışmaya devam ederim. & $\mathbf{3 , 8 7}$ & 944 \\
\hline F7 Yenilikçi Çıktılar & Ortalama & Std. Sapma \\
\hline V21 Fikirlerimi benimsetme ve hayata geçirmede sıklıkla başarılı oldum. & 3,77 & ,747 \\
\hline V22 Düşündüğüm birçok şey kuruluşumuzda uygulanmakta, kullanılmaktadır. & 2,91 & 953 \\
\hline Ne zaman bir yerde çalıștiysam, orada bir şeyleri iyileștirdim & 3,61 & 847 \\
\hline
\end{tabular}

Tablo 3'teki sonuçlara göre "fikir üretimi” alt faktöründe en düşük ortalamayı "İşimi yaparken yeni yollar denerim." maddesi, en yüksek ortalamayı ise; "İşimde bir şeyler iyi gitmediğinde, yeni çözüm yolları bulmayı denerim." maddesinin aldığı görülmektedir. "Fikir Arama" içerisinde yer alan "Kendi işimde yararlanmak için, başka yerlerde işlerin nasıl yapıldı̆̆ı ile ilgilenirim." maddesi en düşük ortalamayı alırken, "Meslektaşlarım veya iş ortaklarımdan yeni fikirler almaya çalışırım.” maddesinin en yüksek ortalamayı aldığı gözlenmiştir. "Fikir İletişimi” içerisinde yer alan "Yeni bir fikrim olduğunda, iş arkadaşlarıma bu fikri benimsetmeye çalışırım.” maddesi en düşük ortalamayı alırken, "Yeni bir fikrim olduğunda, bu fikir üzerinde çalışabilecek insanları işbirliğine dâhil etmeye çalışırım." maddesinin ise; en yüksek ortalamayı aldığı gözlenmiştir. "Uygulamaya Başlama Faaliyetleri” içerisinde yer alan "Yeni fikirlerin uygulanması için uygun planlar ve zaman programları geliştiririm.” maddesi en düşük ortalamayı alırken, "Yeni fikirlerin uygulanması için ihtiyaç duyulan araçları/malzemeleri araştırır, temin ederim.” maddesinin ise; en yüksek ortalamayı aldığı gözlenmiştir. "Diğerlerini Dâhil Etme" içerisinde yer alan "Yeni bir fikrim olduğunda, onu sahiplenecek insanlar bulmaya çalışırım.” maddesi en düşük ortalamayı alırken, "Uygulama sırasında sorunlar ortaya çıkarsa, onları çözebilecek kişilere/ehil ellere teslim ederim” maddesinin ise en yüksek ortalamayı aldığı 
gözlenmiştir. "Engellerin Üstesinden Gelme" içerisinde yer alan "Bir fikri uygularken işler planladığım gibi gitmese bile çalışmaya devam ederim." maddesi en düşük ortalamayı alırken, "Başkaları yapılamayacağını söylediğinde bile pes etmem." maddesinin ise en yüksek ortalamayı aldığ1 gözlenmiş̧ir. "Yenilikçi Çıktı" içerisinde yer alan "Düşündüğüm birçok şey kuruluşumuzda uygulanmakta, kullanılmaktadır." Maddesi tüm ölçekteki en düşük ortalamayı almıştır, buna karşın "Fikirlerimi benimsetme ve hayata geçirmede sıklıkla başarılı oldum." maddesi ise en yüksek ortalamaya sahiptir. Bu durumda kişilerin yenilikleri daha çok bireysel olarak uygulayabilecekleri; fakat kurumsal yenilikçi çıktının oluşması için farklı desteklere ihtiyaç olabileceği görülmüştür. Faktörlerin genel ortalamalarına bakıldığında ise akademisyenlerin fikir üretme ve fikir arama konusunda daha aktif oldukları görülürken fikir iletişimi ve yenilikçi çıktıların diğer faktörlere göre geri planda kaldığı sonucuna ulaşılmıştır.

\section{Sonuç ve Öneriler}

Lukes ve Stephan (2017) tarafindan geliştirilen YDÖ'nün Türkçe uyarlama çalışması sonucunda öncelikle Cronbach Alfa katsayılarının ölçeğin geneli için 0,935; alt faktörleri için de sirasıyla 0,$814 ; 0,767 ; 0,843 ; 0,792 ; 0,793 ; 0,891 ; 0,715$ (fikir üretimi, fikir arama, fikir iletişimi, uygulamaya başlama faaliyetleri, diğerlerini dâhil etme, engellerin üstesinden gelme ve yenilikçi çıktı) olarak güvenilir aralıklarda çıktığı ve ölçeğin kullanılabilir olduğu görülmüş̧ür. Yapılan testler neticesinde Kaiser-Meyer-Olkin (KMO) değerinin 0,912 değeri ile kabul sınırı olarak 0,70 'in üzerinde ve faktör analizi için veri büyüklüğünün uygun olduğu sonucuna varılmıştır. Bartlett küresellik testi sonucunda ise; ortaya çıkan $(\chi 2=1575,853$; s.d. $=253 ; p<0.000)$ değerler ile verilere faktör analizinin uygulanabileceği anlaşılmıştır.

AFA sonucu, ölçeğin orijinal ölçekte olduğu gibi Jolliffe kriterine uyan 7 faktörlü bir yapıya sahip olduğu görülürken bu yedi faktörün ölçeğe dair açıkladığı toplam varyansın \% 74,293 olduğu sonucuna varılmıştır. Varimax metodu ile eksen döndürmesi yapılmış ve sonucunda maddeler en yüksek yüklere göre faktörlere ayrılmıştır. Elde edilen bulgulara göre; yük değerlerinin ilgili faktörler için en az 0,60 ve madde dağılımlarının faktörler için uygun olduğu dikkat çekmiştir. DFA'ya göre de her bir faktör yükünün oldukça yüksek ve anlamlı olduğu gözlenirken, 23 maddenin 20 'si istenen değer olan 0,70 'den büyük ve diğer üç madde de 0,40 'dan büyük faktör yüküne sahiptir. Böylece bu değerlerin kabul edilebilir olduğunu söylemek mümkündür. Yapılan diğer analizlerde AVE değerinin 0,58 olarak hesaplandığı ve böylece modelin yakınsaklık geçerliliğine sahip, CR değerinin alt faktörler için en az 0,70 olarak ortaya çıktığ 1 ve bu değerlerin kabul edilebilir olduğu görülmüştür.

Ele alınan diğer analiz sonuçlarına göre de $\chi 2$ /s.d. değerinin 1,304 olarak elde edildiği böylece modelin iyi uyumlu olduğu, RMSEA değerinin 0,050 ve böylece modelin iyi bir uyuma sahip olduğu; GFI değeri 0,845 ile kritik değere yakın bulunmakla birlikte çalışmadaki örneklem sayısının görece küçük olmasının bu değeri etkilemiş olduğu söylenebilir. CFI değerinin 0,956 olarak ortaya çıktığı ve modelin kabul edilebilirliğini desteklediği ve son olarak IFI değerinin 0,957 olarak ortaya çıktığı ve DFA ile faktör yapısı analiz edilen YDÖ için yedi faktörlü modelin yapısal geçerliliğinin olduğu görülmüştür. Ayrıca, sonuçlarda YDÖ’nün orijinalinde olduğu 
gibi yedi faktörlü elde edilmesi ve yenilikçi davranışlarının yoğun olarak gözlenebildiği akademisyenlerden oluşan veri setinin kullanılması nedenlerinden ötürü faktör yapısını inceleyen analizlerde de genel itibariyle çok büyük bir uyum ve doğrulanma gözlenmiştir.

Özetle, YDÖ’nün Türkçe uyarlama çalışmasına yönelik yapılan analizler sonucunda elde edilen bulgulara göre, bu ölçeğin Türkçe geçerlik- güvenilirliğe sahip olduğu sonucuna varılmıştır. Bu çalışma sayesinde ölçeğin bu haliyle Türkiye'de yapılacak diğer çalışmalarda kullanılabilir olduğu söylenebilir. Daha geniş kapsamda, YDÖ farklı ölçekler ile birlikte bağımlı ya da bağımsız değişken; aracı ya da düzenleyici değiş̧ken olarak kullanılabileceği gibi, nitel araştırma soruları ile de destekleyici ve açılayıcı bir değişken olarak ilgili alanlarda kullanılabilir. Öte yandan, ölç̧ğin bu haliyle farklı sektör ve meslek gruplarında kullanılarak yenilikçi davranışa yönelik algı, tutum ve düşüncelerin değerlendirilmesinin önemli olduğu öngörülmektedir. $\mathrm{Bu}$ sayede, yenilikçi davranışı ölçülebilir ve derecelendirilebilir olduğunun çalışma yaşamı ilgileri arasında kabul göreceği söylenebilir. Bunların yanı sıra, yapılan Türkçe uyarlama çalışması sayesinde, çalışan ve organizasyon özelinde yenilikçi davranış geliştirmeye yönelik modeller ortaya konulabilir, insan kaynağı eğitim ve geliştirme faaliyetlerine yönelik eğitimler tasarlanabilir.

Sonuç olarak, yapılan bu ölçek uyarlama çalışmasının literatüre katkıda bulunarak gelecek araştırmalar için yol gösterici olacağı, Türkiye'de toplanacak verilerin uluslararası karşılaştırmalarda alana katkıda bulunacağı öngörülmektedir.

\section{Kaynakça}

Buckler, B. (1996). A learning process model to achieve continuous improvement and innovation, The Learning Organization, 3(3), 31-39.

De Jong, J.P.J. \& Den Hartog, D.N. (2010). Measuring innovative work behavior. Creativity and Innovation Management, 19(1), 23-36.

Dorenbosch, L., van Engen, M.L. \& Verhagen, M. (2005). On-the-job innovation: The impact of job design and human resource management through production ownership. Creativity and Innovation Management, 14(2),129-141.

Duradoni, M., \& Di Fabio, A. (2019). Intrapreneurial self-capital and sustainable innovative behavior within organizations. Sustainability, 11(2), 322, 1-10.

Evci, N., \& Aylar, F. (2017). Derleme: Ölçek geliştirme çalışmalarında doğrulayıcı faktör analizinin kullanımı. Sosyal Bilimler Dergisi, 4(10), 389-412. 
Farr J.L. \& Ford C.M. (1990). Individual innovation. Managing Innovation (pp.63-80). London: Sage.

Gareth, R.J. (2001), Organizational Theory and Cases, London, Prentice Hall International Inc.

Hair, J.F. Jr., Black, W.C., Babin, B.J. \& Anderson, R.E. (2010). Multivariate Data Analysis (7b.), NJ:Englewood Cliffs, Prentice Hall.

Happell, B., Gaskin, C., \& Platania-Phung, C. (2015). The construct validity of the work-related flow inventory in a sample of Australian workers, The Journal of Psychology: Interdisciplinary and Applied, 149, 42-62.

Jafri, M.H. (2010). Organizational commitment and employees' innovative behavior: A study in retail sector, Journal of Management Research, 10(1), 62-68.

Jolliffe IT. Principle component analysis. Springer, NewYork: 2002.

Kanter, R.M. (1988). When a thousand flowers bloom: Structural, collective and social conditions for innovation in organization. Research in Organizational Behavior, 10, 169211.

Katz, D. \& Kahn, R.L. (1978). The Social Psychology of Organizations. New York: John Wiley \& Sons.

Kheng, Y.K., Mahmood, R. \& Beris, S.J.H. (2013). A conceptual review of innovative work behavior in knowledge intensive business services among knowledge workers in Malaysia. International Journal of Business, Humanities and Technology, 3(2), 93-95.

Kleysen, R.F. \& Street, C.T. (2001). Toward a multi-dimensional measure of individual innovative behavior. Journal of Intellectual Capital, 2(3), 284-296.

Kline, R. B. (2015). Principles and practice of structural equation modeling. Guilford publications.

Krause, D.E. (2004). Influence-based leadership as a determinant of the inclination to innovate and of innovation-related behaviors: An empirical investigation. Leadership Quarterly, 15(1), 79-102.

Lukes, M. \& Stephen, U. (2017). Measuring employee innovation: A review of existing scales and the development of the innovative behavior and innovation support inventories across cultures. International Journal of Entrepreneurial Behaviour \& Research, 23(1), 136-158. 
Mahgoub, A. E. F., Mostafa Shazly, M., \& Mohammed El-sayed, S. (2019). Relationship between work environment and innovative behavior among staff nurses. Egyptian Journal of Health Care, 10(3), 64-77.

Niesen, W., Hootegem, A.V., Elst, T.V., Battistelli, A. \& De Witte, H. (2018). Job insecurity and innovative work behaviour: A psychological contract perspective. Psychologica Belgica, $57(4), 174-189$.

Oldham, G.R., \& Cummings, A. (1996). Employee creativity: Personal and contextual factors at work, Academy of Management Journal, 39(3), 607-634.

Vasanthapriyan, S. (2019). Study of employee innovative behavior in Sri Lankan software companies. In Human Factors in Global Software Engineering (pp. 188-218). IGI Global.

Samuel, C. C. (2000). Modern management diversity, quality, ethics ve the global environment, London: Prentice Hall International.

Scott, S. G. \& Bruce, R. A. (1994). Determinants of innovative behavior: A path model of individual innovation in the workplace. Academy of Management Journal, 37, 580-607.

Shalley, C.E. (1995). Effects of coaction, expected evaluation, and goal setting on creativity and productivity. Academy of Management Journal, 38, 483-503.

Sönmez, B., İspir, Ö., Önal, M., \& Emiralioğlu, R. (2019, January). Turkish psychometric properties of the innovative behavior inventory and innovation support inventory: A model analysis on nurses. In Nursing forum, 54, 254-262.

Tabachnick, B.G. \& Fidell L.S. (2001). Using multivariate statistics. Needham Heights: Allyn \& Bacon.

Thompson, V.A. (1965). Bureaucracy and innovation, Administrative Science Quarterly, 5, 120.

Van De Ven, A. (1986). Central problems in the management of innovation, Management Science, 32, 590-607.

Veenendaal, A. \& Bondarouk, T. (2015). Perceptions of HRM and their effect on dimensions of innovative work behaviour: Evidence from a manufacturing firm. Management Revue. Special Issue: Innovation Networks, 26(2),138-160.

West, M.A. \& Farr, J.L. (1990). Innovation at work. In M. A. West ve J. L. Farr (Eds.), Innovation and creativity at work (pp. 3-13). 
Woodman, R.W., Sawyer, J.E., \& Griffin, R.W. (1993). Toward a theory of organizational creativity. Academy of Management Review, 18(2), 293-321. doi: 10.5465/AMR.1993.3997517

Xerri, M.J. \& Brunetto, Y.O. (2013). Fostering innovative behaviour: The importance of employee commitment and organisational citizenship behaviour. The International Journal of Human Resource Management, 24(16),3163-3177. 